IZA DP No. 10334

The Changing Situation of Labor Market Entrants in Germany: A Long-Run Analysis of Wages and Occupational Patterns

Mario Reinhold

Stephan L. Thomsen

October 2016 


\title{
The Changing Situation of Labor Market Entrants in Germany: A Long-Run Analysis of Wages and Occupational Patterns
}

\author{
Mario Reinhold \\ NIW, Leibniz Universität Hannover \\ Stephan L. Thomsen \\ Leibniz Universität Hannover, \\ ZEW and IZA
}

Discussion Paper No. 10334

October 2016

\author{
IZA \\ P.O. Box 7240 \\ 53072 Bonn \\ Germany \\ Phone: +49-228-3894-0 \\ Fax: +49-228-3894-180 \\ E-mail: iza@iza.org
}

Any opinions expressed here are those of the author(s) and not those of IZA. Research published in this series may include views on policy, but the institute itself takes no institutional policy positions. The IZA research network is committed to the IZA Guiding Principles of Research Integrity.

The Institute for the Study of Labor (IZA) in Bonn is a local and virtual international research center and a place of communication between science, politics and business. IZA is an independent nonprofit organization supported by Deutsche Post Foundation. The center is associated with the University of Bonn and offers a stimulating research environment through its international network, workshops and conferences, data service, project support, research visits and doctoral program. IZA engages in (i) original and internationally competitive research in all fields of labor economics, (ii) development of policy concepts, and (iii) dissemination of research results and concepts to the interested public.

IZA Discussion Papers often represent preliminary work and are circulated to encourage discussion. Citation of such a paper should account for its provisional character. A revised version may be available directly from the author. 


\section{ABSTRACT \\ The Changing Situation of Labor Market Entrants in Germany: A Long-Run Analysis of Wages and Occupational Patterns*}

Concurrently with a steady increase of the supply of college educated workers, recent evidence for the U.S. indicated a decline in the demand for and the real wages of this group after 2000. We investigate empirically, whether there has been a similar trend in Germany. Based on comprehensive, long-run administrative data for the years 1975 to 2010, we use a set of employment indicators to analyze labor market patterns of job market entrants. Besides consideration of the developments of education attainment and wages over time, we put a particular focus on changes of the task composition, the chances of entering top-paying jobs, entry wages and wage growth, and skill premia over time. To allow for a detailed analysis, we distinguish four education groups. The empirical picture shows that since the year 2000 job entrants with higher education have experienced decreasing employment shares in top-paying positions. Moreover, starting wages and wage growth have both decreased, too. A reason for this has been the substitution of jobs that were formerly executed by lower qualifications. Our findings reveal similarities between Germany and the U.S. in terms of some declining fortunes of the young. However, whereas in the U.S. college educated workers have been affected, the results indicate that in Germany the mediumskilled and low-skilled have been particularly impaired.

JEL Classification: J21, J23, J24

Keywords: labor demand, labor supply, occupational sorting, wages, education groups

Corresponding author:

Stephan L. Thomsen

Institut für Wirtschaftspolitik

Leibniz Universität Hannover

Koenigsworther Platz 1

D-30167 Hannover

Germany

E-mail: thomsen@wipol.uni-hannover.de

\footnotetext{
* We would like to thank Bernd Fitzenberger and two anonymous referees for their helpful comments. This study has benefited from discussions at the annual conferences of the European Society for Population Economics, Izmir 2015, the Canadian Economic Association, Toronto 2015, the Associazione Italiana Economisti del Lavoro, Cagliari 2015, and the German Economic Association, Muenster 2015.
} 


\section{Introduction}

During the last decades, Germany and many other countries have experienced an upskilling of the workforce accompanied by a technological shift towards highly-educated labor. Recent evidence for the U.S. labor market indicates declining wages for college graduates in the aftermath of the Tech Bust in 2000, while post-college workers face continuously high employment and wage opportunities (Beaudry et al. 2014, 2016). If similar patterns would have occurred in Germany, this would indicate "declining fortunes of the young" (Beaudry et al. 2014) to be more than a phenomenon of the U.S. labor market.

To investigate empirically, whether there has been a corresponding trend in Germany, we have selected a set of employment indicators to analyze the chances and performance of labor market entrants in Germany over time. We focus on young workers since general changes in the labor market are first apparent for them (Kambourov and Manovskii, 2009). The empirical analysis is based on long-run information of a comprehensive sample of registered employees in the German social security system for the years 1975 to 2010 with about 11.5 million observations. Besides consideration of education attainment and wages overall, we put a particular focus of our study on the developments of the task composition, the chances of receiving a top-paying job, entry wages and wage growth, and wage premia for job market entrants over three and a half decades. Moreover, to allow for a detailed picture we distinguish four different education levels in the analysis. These comprise two distinct types of higher qualification (university and university of applied sciences), medium qualification (persons with completed vocational training in the German apprenticeship system) and low qualification (persons lacking completed vocational education). The data allow conducting a detailed descriptive analysis comparing a large number of job market entry cohorts over time.

Summarizing the empirical picture obtained from the indicators clearly indicates that there was a turning point of the labor market chances of young job market entrants around the year 2000: highlyeducated workers have faced declining employment opportunities in top-paying jobs and, partly, in analytical jobs after 2000. Real entry wages have fallen for each new entry cohort since then. Moreover, wage growth after five years has substantially declined for cohorts entering the labor market in this period in Germany, too. In particular medium-skilled and higher-skilled labor market entrants have been affected by this development. Whereas the share of young high-skilled workers performing analytical jobs has declined only slightly after the tech bust (similar to the U.S.), our results indicate a general decline of wages for young workers. Falling wages are more profound for medium-skilled and lowskilled workers than for high-skilled workers. Wage premia for higher education slightly rose relative to medium-skilled and low-skilled workers. Moreover, the displacement effects, shrinking wages, and flattening wage growth for medium-skilled and low-skilled workers further signify the impacts of the increase in graduation rates in higher education.

The remainder of the paper is organized as follows. The next section gives a more detailed discussion of the related literature for the analysis at hand. Section 3 introduces the data used for the empirical analysis. The empirical results of the considered aspects are presented in section 4 . The final section provides the conclusions. 


\section{Background}

Wage inequality in the U.S. labor market increased during the 1980s, notably at the upper tail of the wage distribution (Katz and Murphy, 1992). In particular, technological change complementing highskilled workers and substituting low-skilled workers contributed as a major driving force to this process (Acemoglu, 2002). Related to this, the skill-biased technological change hypothesis (SBTC) emphasized the exceeding growth in the demand for high-skilled workers with respect to its supply at the expense of less-skilled workers (Katz and Autor, 1999). Despite the convincing characterization in explaining the labor market development during the 1970s and 1980s, more recent literature put stronger focus on the increasing concentration of employment at both tails of the wage distribution associated with a strong decline of medium-skilled occupations. This development hast been called job polarization, e.g. Autor et al. (2003, 2006, 2008); Autor and Dorn (2013), or routine-biased technological change, see Goos et al. (2014).

Increasing wage inequality has long been thought of being a phenomenon solely present in AngloSaxon labor markets. From this perspective, wage inequality in Anglo-Saxon countries and high unemployment rates of low-skilled workers in Continental Europe appeared as 'two sides of the same coin', both stemming from the relative fall in the demand for low-skilled labor (Krugman, 1994). Labor market adjustment in Germany occurred through an alteration of employment rather than wages Antonczyk et al., 2010; Naticchioni et al., 2014).

Despite the developments of the U.S. labor market until the early 2000s, a recent strand of the literature on inequality portrays the demand for high-skilled labor as a boom-bust cycle ceasing with the Tech Bust in 2000. Beaudry et al. (2016) argue that the reversal in the demand for high-skilled workers led to a cascade effect in which college workers perform jobs that have been previously performed by medium-skilled workers, who for their parts pushed low-skilled workers further down on the occupational ladder or even out of employment. Beaudry et al. (2014) underline the trend of an increasing share of the working-age population with a college degree but declining cognitive employment shares, i.e. a declining share of workers in jobs with high intensity of abstract thinking, and declining wages after 2000. In contrast to that, job entrants with a post-college degree faced stable cognitive employment shares and wage profiles.

Starting in the 1990s, rising wage inequality has also been documented for Germany. The high and rising (long-term) unemployment after German reunification forced several fundamental reforms of the labor market. At the same time, wage setting in Germany began to erode due to a diminishing importance of collective bargaining between employer associations and unions (Ochel, 2005). A sharp decline in union coverage, especially at the end of the 1990s accompanied this development and has been shown to explain a major part of the lower tail inequality (Dustmann et al. 2009). In the course of slow growth and persistent unemployment after 2000, the 'sick man of Europe' (The Economist, 1999) reformed the labor market even further (the so-called 'Agenda 2010' reforms). These reforms lowered implicit minimum wages by reducing benefit entitlement with respect to level and duration. All in all, the reforms were particularly designed for decreasing wages and increasing employment at the lower tail of the wage distribution (Dustmann et al., 2014). 
In stark contrast with most European countries, unemployment in Germany was hardly affected neither by the 2008/2009 recession, despite a dramatic fall in gross domestic product, nor the recent Euro crisis. The relative strength of the labor market can be assigned to a number of reasons, including the extensive labor market reforms that have increased flexibility and allowing greater wage inequality and also declining unit labor costs for the past two decades, i.e. productivity growth exceeding wage growth (Dustmann et al., 2014). For that reason, Fitzenberger et al. (2011) note that the process of increasing lower tail wage inequality in Germany was characterized by episodic events, and not due to the lower tail polarization hypothesis suggested by Autor and Dorn (2013). Decomposing wage variance into transitory and permanent parts, Myck et al. (2009) found that permanent inequality peaked in 2001 and declined afterwards. However, a polarization of wages still occurred thereafter but seems to be caused by transitory factors only.

In comparison, the influence of institutional factors upon upper tail wage inequality is limited in Germany. It slightly increased during the 1980s, mainly driven by the changing composition of the workforce (Dustmann et al., 2009). In contrast to the U.S., growth in supply and demand for highskilled workers moved in parallel resulting in less upper tail wage inequality (Acemoglu, 2003). The share of high-skilled workers increased at a roughly linear rate. Similarly to the U.S. in the 1970s (Katz and Murphy, 1992), the expansion in the supply of high-skilled workers occurred at the pace of rising demand for these qualifications (Antonczyk et al., 2010).

Autor et al. (2003) describe that the growth of information and communication technology (ICT) is the crucial trigger for job polarization. ICT has caused a rapid decline of costs due to increasing speed of performing codifiable tasks by computers, which has induced employers to substitute technology for labor. These tasks were characteristic for medium-skilled workers. Advanced communication technologies also support offshoring to foreign worksites for information-based tasks (Blinder, 2007). At the same time, they may enhance the productivity of abstract tasks, such as managing or programming, at the top of the wage distribution where productivity strongly relies upon information as an input $(\mathrm{Au}-$ tor et al., 2003). Over the last decades, the impact of information technology can be supposed to have reached some kind of limit for jobs at the bottom of the wage distribution, where tasks are typically non-routine manual and require non-codifiable physical, verbal or visual activities. The increasing importance of ICT has thus be supposed to have intensified job polarization that complements high-paying jobs and substitutes medium-paying jobs, while only having a small impact on low-paying jobs.

In the past decade, ICT became a general purpose technology affecting the entire economy. The shrinking costs and simplification of usage led to a breakthrough in private households and firms. In 2014, 99\% of German firms had access to the internet (Eurostat, 2015b). Similarly, $89 \%$ of private households in Germany had access to a computer (Eurostat, 2015c). In 2014, 72\% of the individuals used the internet daily (Eurostat, 2015d). Also, computerization and digitalization found its broad way into employment. The share of workers using a computer increased from $45 \%$ in 2003 to $61 \%$ in 2013 (Eurostat, 2015a). Thus, with the increasing coverage of ICT in the workplace, ICT might also gain importance for routine jobs resulting in complementarities rather than substitution, see, e.g., Autor et al. (2014).

However, evidence on the increasing importance of ICT in routine jobs is scarce. Using regional differences in broadband internet coverage, Akerman et al. (2015) show that access to high-speed internet 
further complements skilled workers in non-routine abstract jobs and impairs labor market outcomes of unskilled workers in routine jobs. Moreover, Forman et al. (2012) find that, despite vast internet investment across U.S. counties, only $6 \%$ of the counties with the highest concentration in IT activities before the investment benefit from this investment in terms of wages, while the remaining counties do not. Similarly, Acemoglu et al. (2014) conclude that increasing IT intensity across manufacturing industries does not increase productivity outside computer manufacturing. Hence, a potential reversal of the job polarization hypothesis in the recent decade through a higher adaptability of ICT skills among unskilled workers and higher IT intensity in manufacturing cannot be empirically affirmed. To the contrary, the scarce available evidence indicates that the introduction of ICT in these sectors seems to have further amplified job polarization.

\section{Data}

The empirical analysis is based on data for West Germany for the years 1975 to 2010. Information is taken from the Sample of Integrated Labor Market Biographies (SIAB), a 2 percent random sample of the German social security records provided by the Institute for Employment Research (IAB) containing more than 11.5 million observations. The social security records represent about $80 \%$ of the working population in Germany, excluding e.g. civil servants, soldiers, and self-employed. The data are highly reliable due to the mandatory and administrative nature, where misreporting on wages would cause severe penalties for the employer.

Since the data are obtained from administrative processes, wages are right-censored at the social security contribution assessment ceiling. For male workers, the share of censored wages varies between $9 \%$ and $14 \%$ annually, for women less than $5 \%$ of the wage distribution is censored. However, rightcensoring will only marginally affect our analysis, since we will mainly focus on median wages and on young workers receiving starting wages. For calculating wage premia in the analysis below, we impute wages above the censoring threshold according to Gartner (2005). In line with Dustmann et al. (2009), we further impose the restriction that the daily wage observations is at least 20 Deutschmark (in 1995 DM). In addition, we correct for a structural break of the wage variable from 1983 to 1984, when bonus payments have been included in the data. Thereby, we follow the approach by Dustmann et al. (2009) which extends the solution suggested by Fitzenberger (1999). Lastly, we adjust wages to inflation.

To investigate the role of education level, we distinguish between four types of education with two types of higher education. Graduates from university are the highest skill group in this classification (high-uni-skilled), the second highest group consists of graduates from university of applied sciences (Fachhochschule, high-fh-skilled). It refers to graduation from a unique kind of tertiary schools in German-speaking countries. The major distinction between the two high-skilled groups is that university has a more theoretically-based education and usually longer duration of education (at least until the implementation of the so-called Bologna reform, introducing Bachelor and Master degrees at all tertiary education institutions in Germany). The university of applied sciences is further characterized by a lower focus on abstract skills. Enrollment in university of applied sciences requires a technical diploma (Fachabitur) with lower admission criteria; for university, students generally need to possess a university-entrance diploma (Abitur). The on average shorter duration is also reflected by a younger age 
of labor market entry. The International Standard Classification of Education (ISCED) of 1997 classified university of applied sciences and university both as tertiary-type A (OECD, 2014). In the 2011 classification (OECD, European Union, UNESCO Institute for Statistics, 2015), university of applied sciences (Germany) is assigned level 6, i.e. programs designed to provide intermediate academic skills leading to a first degree with a typical duration of three to four years. University (Germany) is defined as level 7, covering scientifically more complex studies designed to provide advanced academic skills leading to a second degree. In addition to these two groups, we regard medium-skilled workers who completed a vocational training in the German apprenticeship system, and low-skilled workers without any formal vocational qualification.

To analyze the composition of tasks over time, jobs are assigned to tasks according to the classification by Dengler et al. (2014) for the year 2011 (annual variation of the task composition is low). It is comparable to the U.S. dictionary of occupational titles. Each occupation is composed of five tasks, the main task is determined by the largest task fraction: (1) analytical non-routine (e.g. research, evaluation, planning, interpret rules), (2) interactive non-routine (e.g. negotiate, teach, entertain, manage personnel), (3) cognitive routine (e.g. calculating, measuring, book-keeping), (4) manual routine (e.g. operate, control machines), and (5) manual non-routine (e.g. repair, renovate, restore, nurse).

Finally, we have imposed a number of restrictions on the analysis sample for consistency reasons. Since exact information on working hours is not recorded in the data we consider only full-time employed persons. Moreover, the education variable is subject to missing values and inconsistencies as noted by Fitzenberger et al. (2005). We correct it using forward and backward extrapolation. The analysis sample contains only employees between 20 and 60 years of age; we will focus on the age group between 25 and 35 years in particular. Since labor market entry is not directly observable in the data, we approximate it by potential experience calculated as the difference between the individual age and the typical qualification-controlled starting age in the labor market. Assuming that at age 35 the final education attainment has been reached, we compute the fraction of observations for each education attainment and age group based on the number of observations for each education attainment at age 35 . The typical age of labor market entry is then defined as the age, where the fraction exceeds $50 \%$. This is 19 years for low-skilled, 20 years for medium-skilled, 26 for high-fh-skilled and 28 for high-uni-skilled workers.

\section{Empirical Results}

\subsection{A Review of Trends in Education and Wage Development}

Germany faced a constant increase in educational attainment. The left panel of figure 1 shows the distribution of the four education levels for young workers over time. The number of young workers without any vocational qualification has decreased considerably - from about one quarter in 1975 to about one tenth in 2010. Obviously, workers with vocational training (medium-skilled) are the backbone covering more than two thirds of the young labor force over the whole time span. The share of mediumskilled workers had grown until the mid-1990s at the expense of low skills. Its share has declined from then onwards at the expense of higher education. The share of young workers with higher education had 
doubled from the mid-1970s to the mid-1990s - but was still of smaller importance by the mid-1990s with $14 \%$ of the working population only. The growth of the share of high-skilled workers has gained pace thereafter, notably for high-uni-skilled workers. By 2010, more than one quarter of the young workforce has completed higher education; and the share high-uni-skilled workers has been larger then the share of workers without vocational training.

$$
<\text { Include Fig. } 1 \text { about here }>
$$

This impression fully reverses, however, when regarding absolute numbers, which are displayed in the right panel. The proportional shift observed for shares of education attainment is not present anymore. Although the share of high-skilled workers increased over time and doubled from 1995 to 2010, the absolute number has remained nearly constant. Beginning in the 1990s, the effects of demographic change in Germany have induced a sharp decrease in the number of young persons 1 The number of 25 year-old persons had decreased from 1990 to 1999 by more than one third and has maintained this level during the 2000s (East and West Germany combined) 2 Due to that, even though the relative number of high-skilled workers has increased continually, it is important to note that the absolute number has hardly changed.

How did these shifts of the skill distribution affect the wage structure? Figure 2 displays the development of log median daily wages separately for experienced workers between 36 and 60 years and for younger workers ( 25 to 35 years of age). The median real wage had increased monotonously from 1975 to 1990 - with a short episode of negative growth between 1980 and 1982. This process was followed by a volatile but more or less stable development of wages during the 1990s. After 2003, real wages have started to decrease for all workers but more considerably for the group of young workers.

$$
<\text { Include Fig. } 2 \text { about here }>
$$

More importantly, the figure indicates that the wages of experienced workers and that of young workers have started to diverge over time. In the beginning of the sample period, the wage gap between young and experienced workers was merely $3 \%$. It has increased to $16 \%$ until 2010 . The growing wage gap has occurred in two periods, namely until 1990, and after the year 2002/2003, coinciding with the Tech bust and the implementation of the 'Agenda 2010' labor market reforms in 2003. This evidence may be interpreted as a rise in wage inequality, notably for the young (and) labor market entrants, see e.g. Gernandt and Pfeiffer (2007), Antonczyk et al. (2010) or Eichhorst and Tobsch (2014).

\subsection{Are There Declining Fortunes of the Young in Germany?}

\section{The Task Composition of Young Workers}

While the workforce has become more skilled due to the increasing share of high-skilled workers, the average employment share of non-routine analytical tasks has remained largely stable. This can imply

\footnotetext{
${ }^{1}$ Until the mid 1960s, Germany grew strong due to a pronounced "baby boom" generation. However, it was followed by a lack of subsequent strong birth cohorts and 1964 to 1974, the number of births shrunk by roughly $41 \%$.

${ }^{2}$ The decreases in other industrialized countries were much smaller, e.g. about $4.5 \%$ in metropolitan France, $19.4 \%$ in the United Kingdom, and $12.1 \%$ in the U.S. (Eurostat 2015e, U.S. Census Bureau 2012).
} 
some kind of occupational downgrading for high-skilled workers. It would be likely if the average task share of non-routine analytical tasks has shrunk for high-skilled workers. Therefore, we decompose the average task performance by education groups to reveal a potential shift of high-skilled workers to jobs that do not require their expected analytical skills.

Figure 3 displays these shifts in the task performance. The average employment share in analytical jobs is sorted according to education attainment. Expectedly, it is highest for employees with a university degree and lowest for persons without vocational training. Overall, the average shares show a high persistence but there had been a small decline for high-skilled workers until 1985. For the high-fhskilled workers, we further observe a decrease after 2000. However, the share of non-routine analytical tasks for each education group has maintained a rather stable level over time, which can be interpreted as an equilibrium between the increasing demand for analytical tasks and the educational expansion in Germany. This is in line with findings of Beaudry and Green (2003).

$$
<\text { Include Fig. } 3 \text { about here }>
$$

The non-routine interactive employment share that - has slightly increased for the young workforce overall - has decreased for high-uni-skilled until the mid-1990. For the high-fh-skilled workers, it has remained stable after 1990. Contrary to that, a rise of importance can be established for routine cognitive tasks for high-skilled workers until 1997. After that year, however, their fraction in the task composition has begun to fall slowly. For the high-fh-skilled, the share has risen similarly until the mid-1990s, and has maintained that level more or less since then. For high-skilled workers, routine manual and nonroutine tasks have played a minor role only over the whole period of analysis.

To summarize, the empirical figures indicate that the share of high-skilled workers performing nonroutine analytical jobs has remained constant. Also, the employment share of routine cognitive jobs has not changed for high-skilled workers. Therefore, a clear cascading pattern - as described in Beaudry et al. (2014) - cannot be confirmed for the two groups of high-skilled workers in Germany. Nevertheless, the increase of high-skilled workers in routine cognitive jobs may hint at an academization of these jobs. For the high-uni-skilled, the share of routine cognitive tasks has increased continuously at the expense of non-routine interactive tasks, whereas the remaining task shares have remained on rather constant levels over time. For the high-fh-skilled, the share of routine cognitive tasks has increased similarly at the expense of two groups: on the one hand, the shares of non-routine analytical tasks before 1985 and after 2003 have decreased, and on the other hand, non-routine interactive tasks had decreased between 1987 and 1992. By and large, these quite persistent patterns of the task composition do not provide unambiguous indications for the declining wages of the young.

\section{Development of Young Workers in Top-Paying Jobs}

Do high-skilled labor market entrants receive the best-paying jobs? To answer this question, we order jobs according to their average wage over all years. We distinguish between three job categories: toppaying jobs pay above the 70th wage percentile, bottom-paying jobs below the 30th wage percentile; all other jobs are referred to as medium-paying. Figure 4 plots the developments and shares of labor market entrants with four to six years of potential experience in the three job categories over time and takes the 
different levels of education into account. First of all, with regard to all young workers independently of education level the share of those employed in top-paying occupations after four to six years of experience had risen from $14 \%$ (1975) to $21 \%$ (1998), but has stagnated thereafter. Moreover, the main rise has occurred during the 1990s. At the same time, the fraction of workers in the bottom-paying jobs has remained largely constant over the full observation period with a small increase after 2003. Hence, these patterns imply that the shift towards more workers in top-paying occupations reflects a declining share of workers in medium-paying jobs.

$<$ Include Fig. 4 about here $>$

To get a more detailed picture, distinguishing between education attainments can further reveal the adverse opportunities for high-skilled workers in recent years. As becomes obvious from the pattern, university graduates have faced a decreasing chance of working in top-paying jobs. The fraction declined from $81 \%$ (1985) to $72 \%$ (2010). A major part of this drop has occurred after the year 2000 and notably in support of medium-paying jobs. The shift is similarly profound for high-fh-skilled workers, who have also faced a drastic drop in top-paying jobs from 72\% to 58\% between 2000 and 2010 in favor of medium-paying jobs.

In line with this, the picture for medium-skilled workers shows that the chance of obtaining a mediumpaying job has slightly fallen after the year 2000, concurrently with an increasing share in bottompaying jobs. A similar pattern can also be derived for low-skilled workers. Their chances of obtaining a medium-paying job have constantly fallen, especially after 1995, and the risk of obtaining a bottompaying jobs has increased and has surpassed the share of medium-paying jobs by 2010 .

Hence, with respect to job quality we find a clear cascading pattern across skill groups after 2000, which may hint at an oversupply of high-skilled workers (since skills have grown over time, see above). Although the share of all young workers in top-paying jobs has remained relatively stable over the 2000s (after an increase over the 1990s), for the groups of high-skilled workers clear declines in the respective shares have to established. This means that less young workers have obtained a top-paying job after 2000. On the contrary, their share in medium-paying jobs has risen continuously. Concurrently with that, the share of medium- and low-paying workers in medium-paying jobs has shrunk, while - vice versa - their share in bottom-paying jobs has increased. These patterns clearly indicate that relatively better skilled groups have crowded out relatively lower skilled groups in Germany - at least over the first decade of this century.

\section{Wage Growth and Entry Wages over Time}

The empirical results just presented document a cascading pattern across skill groups since the year 2000 in Germany. At the same time, the level of skills, and in particular the share of high-skilled young workers overall, have increased tremendously. This translates into a rather stable job ordering for all young workers (top left panel in figure 4). Figure 2 above displayed that the increasing wage gap between the young and the experienced workers has widened notably after 2003. The stable shares in top-, medium- and low-paying jobs and the contemporaneously rising wage gap from 2003 onwards can 
therefore only be reconciled with declining wages within jobs or falling skill premia. Wages and wage growth must have fallen over time for young workers - independently of their skills.

Figure 5 provides empirical evidence on this development. It shows how job entrants have performed in their first five years of work with consideration of education attainment and potential experience. Each line refers to two consecutive annual entry cohorts. As becomes obvious, starting wages and wages after five years have both tended to increase until the year 2000. After that year, however, entry wages have started to fall. Moreover, wage growth slowed down considerably (indicated by the shorter wage profiles), resulting in lower wages after five years of work. These are quite important findings for understanding the changing situation for labor market entrants in Germany.

\section{$<$ Include Fig. 5 about here $>$}

Looking at the changes around the turn of the century in more detail (see also Table A1 in the appendix), the initial five-year wage growth declined for high-uni-skilled workers from about $28 \%$ (1996/97-cohort) to 19\% (2002/03-cohort). Over the same period, newly arriving cohorts of the highfh-skilled were faced with an even stronger reduction from $32 \%$ to $14 \%$. All other groups experienced quite substantial declines of wage growth, too; from about $20 \%$ to $10 \%$ for medium-skilled and from about $24 \%$ to $19 \%$ for low-skilled workers. Hence, the moderation of wage growth affected all skill groups.

However, when taking the long-run developments into account the picture indicates some kind of cyclicality in wage growth for high-skilled workers: wage growth and entry wages increased for cohorts entering the labor market after the mid-1980s. However, this was counteracted by declining wage growth and entry wages in the early 1990s. This event repeated a decade later, with increasing wage growth from the mid-1990s and falling wage growth from the early 2000s. In contrast to these patterns for the highskilled, entry wages and wage growth for low-skilled workers have already started to fall from the early 1990s onwards, and wage growth for medium-skilled workers has shrunk continuously from the 2000s.

This cyclicality in wages and wage growth, promptly accelerating for cohorts entering the labor market in the mid-1990s and recapturing its former path after the millennium, still cannot completely explain the increasing wage gap between young and experienced workers (see figure 2 above). The cyclicality can be observed for both high-uni and high-fh-skilled workers, and there is no convergence to narrowing the wage gap between young and experienced workers in the late 1990s. At the same time and in contrast to the higher-skilled groups, there is no cyclical movement for medium- and low-skilled workers: medium-skilled young workers had faced constant wages and wage growth in the 1990s, which have declined after the millennium. For low-skilled workers, the corresponding fall in wages has begun already a decade earlier. Both developments are easy to reconcile with falling chances to obtain medium-paying jobs and increasing risks to get bottom-paying jobs as well as the cascading pattern across skill groups, starting by the millennium for medium-skilled workers and about a decade earlier for low-skilled workers. Still, the increasing wage gap between young and experienced workers is difficult to explain in light of the increasing share of high-skilled workers and the declining share of medium- and low-skilled workers. Hence, a further possible reason for the wage gap remains in a decline of wage premia for skills, i.e. lower returns to education levels over time. 


\section{Wage Premia}

Having discussed aspects of education, jobs and wages, we will consider the development of returns to education (wage premia) over time as the final step in analyzing the chances of job market entrants. Declining opportunities of young high-skilled workers getting a high-paying job can also result in lower wage premia for higher degrees, see e.g. Pikos and Thomsen (2016). We estimate a variant of the Mincer earnings equation that considers the effect of potential experience, education level (categorical) and gender (dummy). We augment the model in a second step by dummy variables for tasks (reference category: non-routine manual jobs) ${ }^{3}$ To analyze wage premia over time, we estimate the models for each year separately.

Figure 6 plots the estimated coefficients of wage premia to education levels over time, both with and without controlling for tasks (left and right panel). Wage premia have continually increased from the mid-1990s for high-skilled individuals. The wage premium for the medium-skilled, however, has increased only slightly. The wage gap between medium-skilled and high-skilled workers, therefore, has widened over time. Higher education, independently of having a degree from a university or from a university of applied sciences was thus associated with an increasing wage premium relative to low and medium education. Nevertheless, the gaps in the wage premia between the different groups of higher education have remained rather persistent over the whole analysis period.

\section{$<$ Include Fig. 6 about here $>$}

When task groups are considered in the estimation, they reduce the absolute level and the relative increase of the estimated wage premia of high-skilled workers. Despite this level effect, the relative increase of wage premia has followed a similar pattern. For high-skilled workers, wage premia have increased after the mid-1990s, but the rise has been smaller in size. However, the increase in the wage premium of medium-skilled workers relative to low-skilled workers has halved when taking the effects of tasks into account. Both panels show the increase in wage premia relative to low-skilled and mediumskilled workers. Figures 4 and 5 above revealed already a decline of starting wages for low-skilled workers. The increase in wage premia of high-skilled workers may thus further imply a relative fall of demand and of wages for low-skilled workers. With respect to the timing, it should be noted that most of the increase of the wage premia has occurred after the mid-1990s. From the beginning of the 2000s, however, real wages of high-skilled labor market entrants have fallen, but not as strong as those of low-skilled and medium-skilled workers.

\section{Conclusion}

With the aim of providing a picture of the labor market chances of job market entrants in Germany, we have analyzed the labor market patterns of this group over a long period of time from 1975 to 2010

\footnotetext{
${ }^{3}$ It should be noted that task groups are very likely to correlate with education or may even be partially determined by it. Therefore, they could be seen - to some extent - as potentially endogenous. Nevertheless, there is still a considerable amount of variation between education and tasks, i.e. tasks are no direct mapping of education. We try to control for this variation in the respective specification of the Mincer equation.
} 
considering aspects of education attainment, wages and jobs. The empirical results indicate that real wages had stagnated from the mid-1990s onwards and have even declined since the mid-2000s, a period characterized by an increasing importance of ICT. Also since the mid-1990s, the share of young workers with a higher education attainment has started to increase markedly in Germany. At the same time, a shrinking size of young cohorts reveals the effects of the accelerated demographic change.

We demonstrate that the wage gap between young and experienced workers has increased over time, although the absolute cohort size of young workers has declined and the share of high-skilled young workers has increased. In contrast to the findings for the U.S., this is associated with a slight decline in the chances of high-skilled workers to obtaining analytical jobs only. At the same time, however, we have found a clear decrease in the opportunity of young workers to work in top-paying jobs. Although the share of young workers in top-paying occupations has overall risen (particularly during the 1990s), the chances of obtaining a top-paying occupation have fallen significantly for high-skilled labor market entrants. Besides the reduced probability of getting a top-paying job, wage growth has declined substantially, in particular for the two groups of high-skilled workers considered and for medium-skilled workers. Nevertheless, taking the long-run picture into account, our empirical evidence does not speak for a distinct reversal in wage expectations of high-skilled workers. Although wage growth for cohorts entering the labor market after 2000 has been smaller than for cohorts entering in the 1990s, it recaptured its magnitude from around the year 1990. For medium-skilled labor market entrants, in contrast, wages and wage growth have continually and remarkably declined.

The most important results of our analysis are the indications of a cascading pattern in which the decline in the share of labor market entrants in top-paying jobs was profound for high-uni-skilled workers and for high-fh-skilled workers. In addition, the share of high-skilled workers in medium-paying jobs increased at the expense of the share in top-paying jobs. The shares of medium-skilled and lowskilled workers in bottom-paying positions have risen, while the share of medium-paying jobs has fallen. Hence, in difference to the results reported for the U.S. by Beaudry et al. (2014) that report pronounced effects for college graduates, our results confirm some kind of cascade of jobs, but it is not limited to the group of high-skilled workers. The analysis of the development of wage premia to education levels over time can be interpreted as evidence in the opposite direction: within the two considered groups of high-skilled, wage premia have remained rather stable over time and have even grown relative to medium-skilled and low-skilled workers. Nevertheless, the results overall indicate some similarities between the trends of the U.S. and the German labor market during the last decade with regard to displacement effects of lower qualifications. However, the obtained patterns differ in terms of the particular skill groups affected.

\section{References}

Acemoglu, D. (2002). Technical Change, Inequality, and the Labor Market. Journal of Economic Literature, 40(1):7-72.

Acemoglu, D. (2003). Cross-Country Inequality Trends. The Economic Journal, 113(485):F121-F149.

Acemoglu, D., Autor, D., Dorn, D., Hanson, G. H., and Price, B. (2014). Return of the Solow Paradox?

IT, Productivity, and Employment in US Manufacturing. American Economic Review, 104(5):394-99. 
Akerman, A., Gaarder, I., and Mogstad, M. (2015). The Skill Complementarity of Broadband Internet. NBER Working Papers 20826, National Bureau of Economic Research, Inc.

Antonczyk, D., DeLeire, T., and Fitzenberger, B. (2010). Polarization and rising wage inequality: comparing the US and Germany. ZEW Discussion Papers 4842, Centre for European Economic Research.

Autor, D., Dorn, D., Hanson, G. H., and Song, J. (2014). Trade Adjustment: Worker Level Evidence. IZA Discussion Papers 8514, Institute for the Study of Labor.

Autor, D. H. and Dorn, D. (2013). The Growth of Low-Skill Service Jobs and the Polarization of the US Labor Market. American Economic Review, 103(5):1553-97.

Autor, D. H., Katz, L. F., and Kearney, M. S. (2006). The Polarization of the U.S. Labor Market. American Economic Review, 96(2):189-194.

Autor, D. H., Katz, L. F., and Kearney, M. S. (2008). Trends in U.S. Wage Inequality: Revising the Revisionists. The Review of Economics and Statistics, 90(2):300-323.

Autor, D. H., Levy, F., and Murnane, R. J. (2003). The Skill Content of Recent Technological Change: An Empirical Exploration. The Quarterly Journal of Economics, 118(4):1279-1333.

Beaudry, P. and Green, D. A. (2003). Wages and Employment in the United States and Germany: What Explains the Differences? American Economic Review, 93(3):573-602.

Beaudry, P., Green, D. A., and Sand, B. M. (2014). The Declining Fortunes of the Young since 2000. American Economic Review, 104(5):381-86.

Beaudry, P., Green, D. A., and Sand, B. M. (2016). The Great Reversal in the Demand for Skill and Cognitive Tasks. Journal of Labor Economics, 34(1):199-247.

Blinder, A. S. (2007). How Many U.S. Jobs Might Be Offshorable? Working Papers 142, Princeton University Center for Economic Policy Studies.

Dengler, K., Matthes, B., and Paulus, W. (2014). Occupational Tasks in the German Labour Market. FDZ Methodenreport, Institute for Employment Research.

Dustmann, C., Fitzenberger, B., Schönberg, U., and Spitz-Oener, A. (2014). From Sick Man of Europe to Economic Superstar: Germany's Resurgent Economy. Journal of Economic Perspectives, 28(1):16788.

Dustmann, C., Ludsteck, J., and Schönberg, U. (2009). Revisiting the German Wage Structure. The Quarterly Journal of Economics, 124(2):843-881.

Eichhorst, W. and Tobsch, V. (2014). Not So Standard Anymore? Employment Duality in Germany. IZA Discussion Papers 8155, Institute for the Study of Labor.

Eurostat (2015a). Employees - availability of computers (NACE Rev. 2 activity). Web: http://ec.europa.eu/eurostat/data/database. Retrieved October 07, 2015. 
Eurostat (2015b). Enterprises - level of internet access (NACE Rev. 2 activity). Web: http://ec.europa.eu/eurostat/data/database. Retrieved October 07, 2015.

Eurostat (2015c). Households - availability of computers. Web: http://ec.europa.eu/eurostat/data/database. Retrieved October 07, 2015.

Eurostat (2015d). Individuals - frequency of internet use. Web: http://ec.europa.eu/eurostat/data/database. Retrieved October 07, 2015.

Eurostat (2015e). Population on 1 January by age and sex. Web: http://ec.europa.eu/eurostat/data/database. Retrieved August 20, 2015.

Fitzenberger, B. (1999). Wages and employment across skill groups: an analysis for West Germany. Physica-Verlag.

Fitzenberger, B., Kohn, K., and Wang, Q. (2011). The erosion of union membership in Germany: determinants, densities, decompositions. Journal of Population Economics, 24(1):141-165.

Fitzenberger, B., Osikominu, A., and Völter, R. (2005). Imputation Rules to Improve the Education Variable in the IAB Employment Subsample. ZEW Discussion Papers 05-10, ZEW - Zentrum für Europäische Wirtschaftsforschung.

Forman, C., Goldfarb, A., and Greenstein, S. (2012). The Internet and Local Wages: A Puzzle. American Economic Review, 102(1):556-75.

Gartner, H. (2005). The imputation of wages above the contribution limit with the German IAB employment sample. Technical Report 2/2015, FDZ method report.

Gernandt, J. and Pfeiffer, F. (2007). Rising Wage Inequality in Germany. Journal of Economics and Statistics, 227(4):358-380.

Goos, M., Manning, A., and Salomons, A. (2014). Explaining Job Polarization: Routine-Biased Technological Change and Offshoring. American Economic Review, 104(8):2509-26.

Kambourov, G. and Manovskii, I. (2009). Occupational Mobility and Wage Inequality. Review of Economic Studies, 76(2):731-759.

Katz, L. F. and Autor, D. H. (1999). Changes in the wage structure and earnings inequality. In Ashenfelter, O. and Card, D., editors, Handbook of Labor Economics, volume III of Handbook of Labor Economics, chapter 26, pages 1463-1555. Amsterdam: Elsevier.

Katz, L. F. and Murphy, K. M. (1992). Changes in Relative Wages, 1963-1987: Supply and Demand Factors. The Quarterly Journal of Economics, 107(1):35-78.

Krugman, P. (1994). Past and prospective causes of high unemployment. Economic Review-Federal Reserve Bank of Kansas City, 79:23-23.

Myck, M., Ochmann, R., and Qari, S. (2009). Dynamics of Earnings and Hourly Wages in Germany. DIW Discussion Papers 929, German Institute for Economic Research. 
Naticchioni, P., Ragusa, G., and Massari, R. (2014). Unconditional and Conditional Wage Polarization in Europe. IZA Discussion Papers 8465, Institute for the Study of Labor (IZA).

Ochel, W. (2005). Decentralizing Wage Bargaining in Germany - A Way to Increase Employment? LABOUR, 19(1):91-121.

OECD (2014). Education at a Glance 2014: OECD Indicators. Technical report, OECD Publishing.

OECD, European Union, UNESCO Institute for Statistics (2015). ISCED 2011 Operational Manual: Guidelines for Classifying National Education Programmes and Related Qualifications. Technical report, OECD Publishing.

Pikos, A. K. and Thomsen, S. L. (2016). Rising Work Complexity But Decreasing Returns. IZA Discussion Paper 9878, Institute for the Study of Labor, Bonn.

The Economist (1999). The sick man of the Euro. The Economist. June 1999.

U.S. Census Bureau (2012). National Intercensal Estimates (1990-2000). Web: http://www.census.gov/popest/data/intercensal/national/files/US-EST90INT-09.csv. Retrieved August 20, 2015.

vom Berge, P., König, M., Seth, S., et al. (2013). Sample of Integrated Labour Market Biographies (SIAB) 1975-2010. Technical Report 01/2013, FDZ data report. 


\section{Tables and Figures}

Figure 1: Education Distribution (Shares, 25-35 Years, 1975-2010)
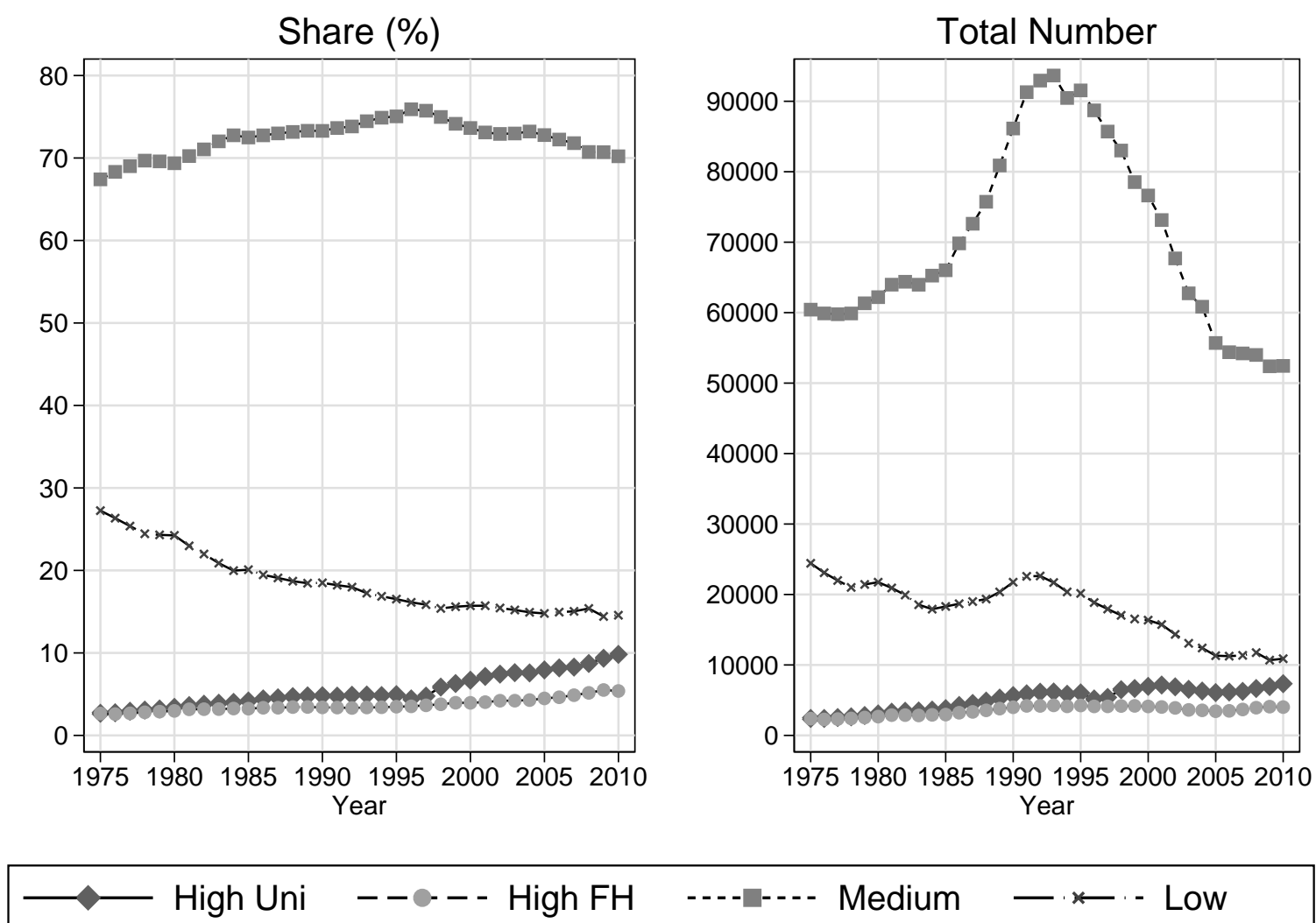

-.---. Medium -

Source: $2 \%$ IABS Sample for full-time workers between 25 and 35 years of age. N=3,489,383. 
Figure 2: Median Log Real Daily Wages of Experienced Workers and of Young Workers (1975-2010)

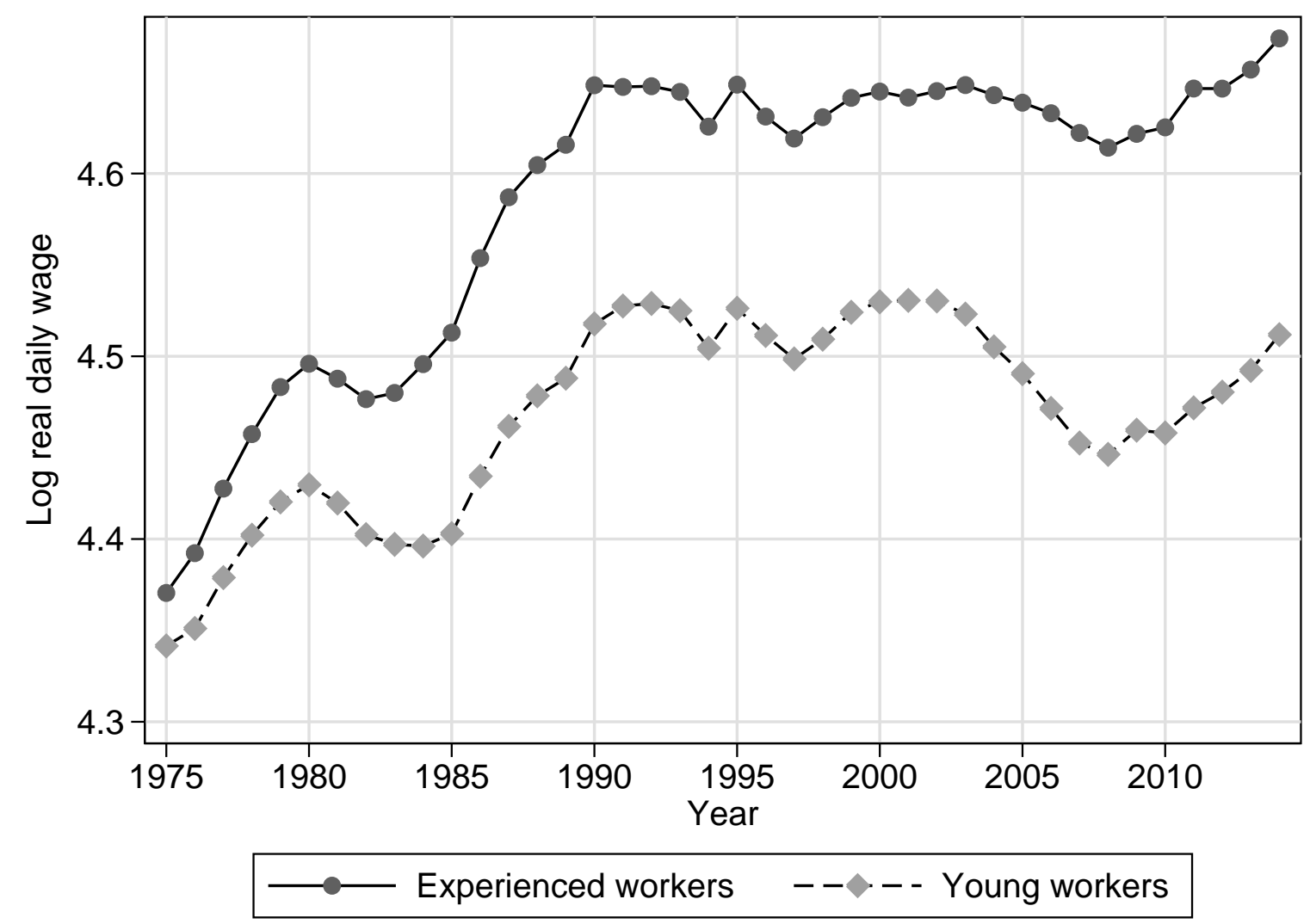

Source: $2 \%$ IABS Sample for full-time workers. N=7,182,868 for experienced workers (36 to 60 years) and N=3,752,250 for young workers ( 25 to 35 years). 
Figure 3: Shares of Performed Tasks (Education Groups, 25-35 Years)
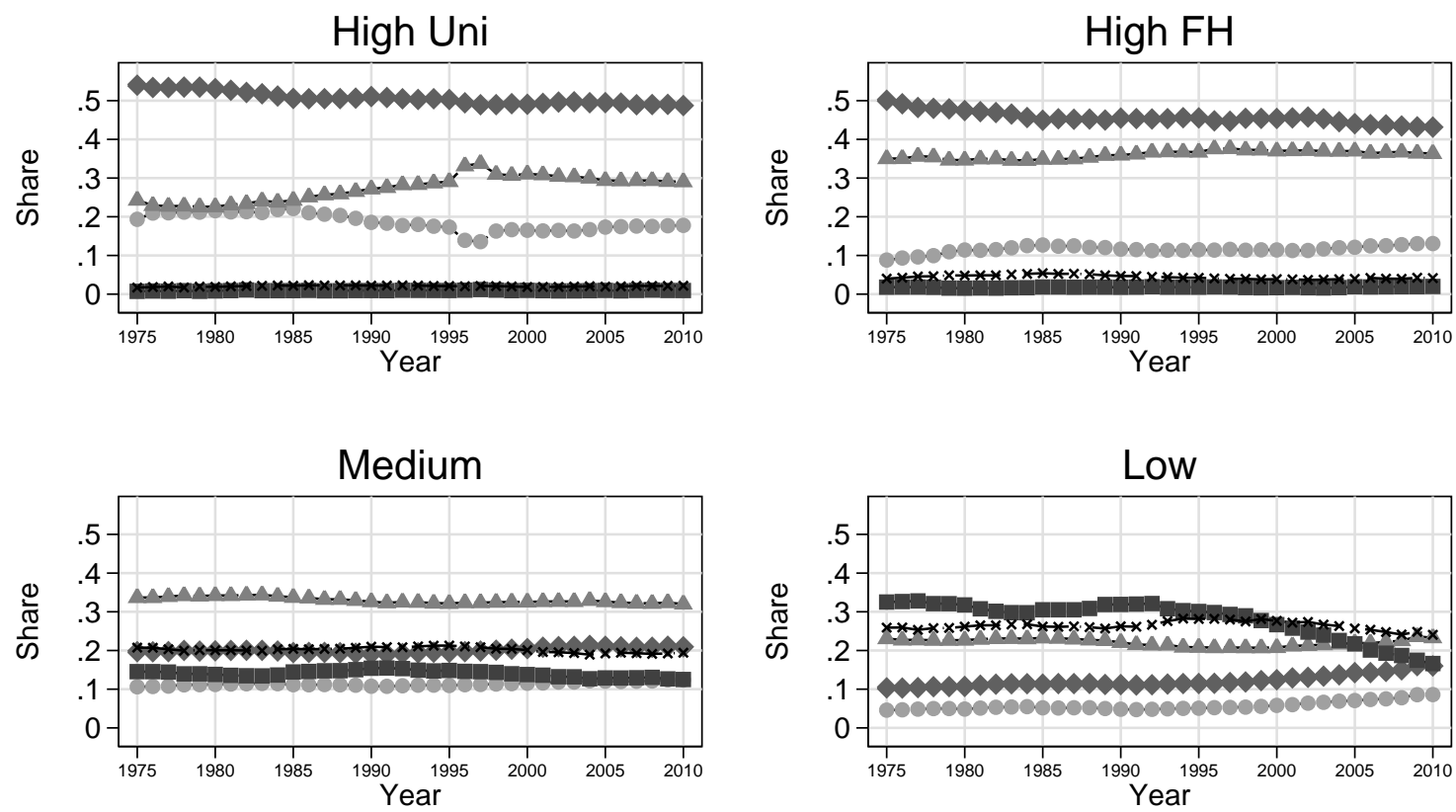

$$
\begin{array}{ll}
- \text { Non-routine analytical } & --\cdots-\text { Non-routine interactive } \\
-\_- \text {Routine cognitive } & -\ldots-\text { Routine manual }
\end{array}
$$

Source: $2 \%$ IABS Sample for full-time workers between 25 and 35 years of age. N=3,754,656.

The kinks for the high-uni-skilled workers stem from an underpresentation of doctors and pharmacists in the years 1996 and 1997 in the sample, see vom Berge et al. (2013). 
Figure 4: Job Ordering (Four to Six Years of Experience)
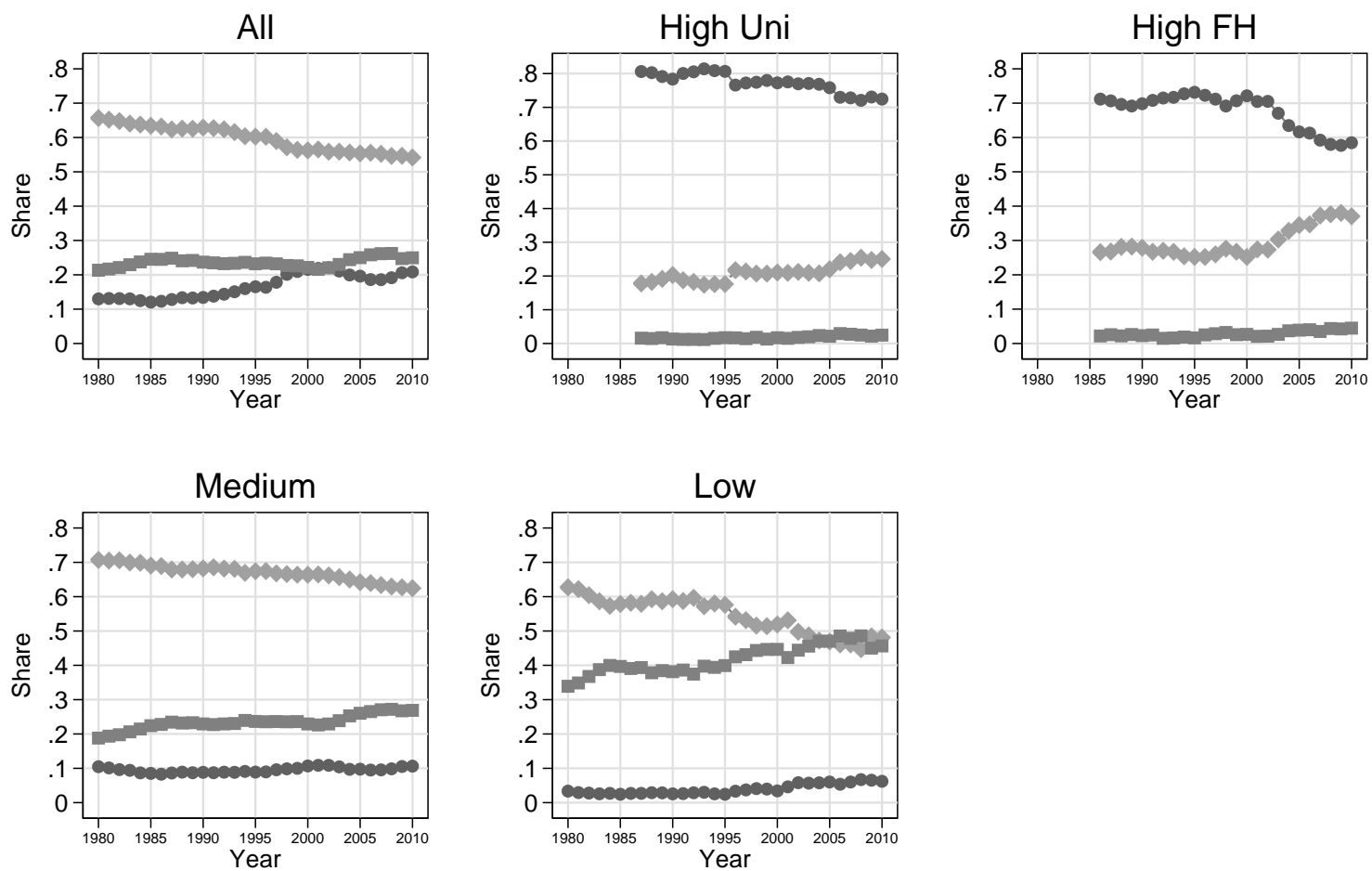

$$
\longrightarrow \text { Top } \longrightarrow-\uparrow-- \text { Medium } \quad-\text { - - Bottom }
$$

Source: 2\% IABS Sample for full-time workers between 25 and 35 years of age with information on job. N=2,000,214 for all workers.

Note: Jobs are ordered according to their mean wage and assigned to a percentile in the wage distribution. The calculation of mean wages is based on imputed wages following Gartner (2005). Top-jobs have a mean wage above the $70 \%$ percentile, bottom-jobs below the $30 \%$ percentile, the remain jobs are considered as medium-jobs. Lines represent annual shares of workers with four to six years of potential experience. 
Figure 5: Median Log Real Daily Wage Profiles for Labor Market Entrants (Potential Experience)

High Uni
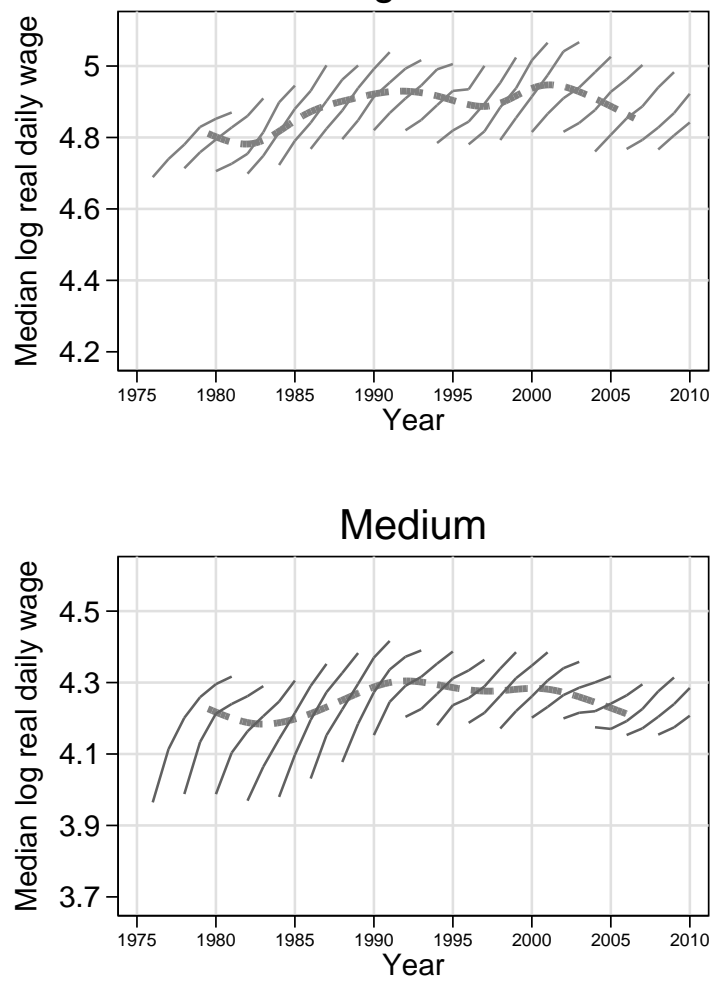

High FH
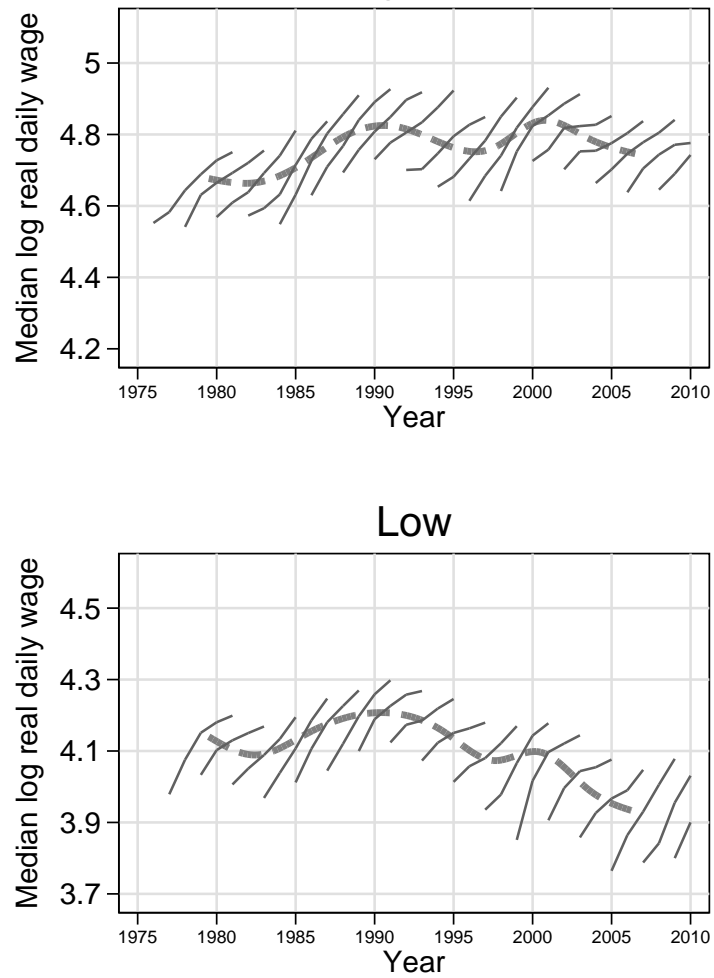

Source: $2 \%$ IABS Sample for full-time workers with less than five years of potential experience and a positive log real daily wage. $\mathrm{N}=1,703,254$.

Note: Displayed are log real median wage by potential experience for two-year-cohorts (solid lines). Dashed lines denote the median wage for each cohort from 1976/77 to the 2006/07 cohort in the first five years of labor market entry. See Table A1] in the appendix for further information. 
Figure 6: Wage Premia for Education Groups (25 to 35 years)
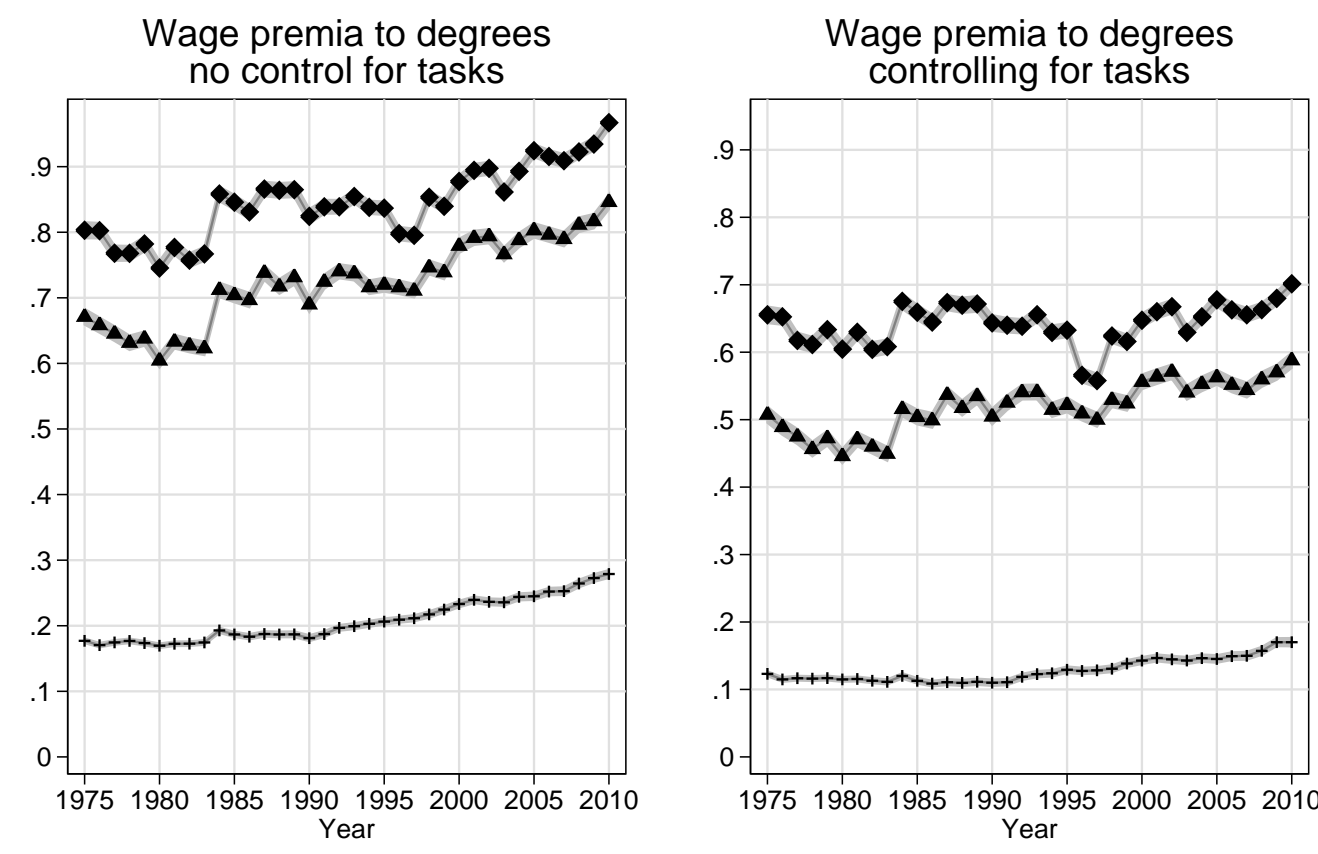

$\checkmark$ High Uni $\longleftarrow$ High FH $\longleftarrow$ Medium $\quad 95 \%$ Conf.

Source: $2 \%$ IABS Sample for full-time workers between the age of 25 and 35 years. Left panel: N=6,738,035. Right panel: 6,569,463.

Note: Wage premia are indicated by coefficients obtained from year-by-year estimations of Mincer earnings equations with education attainment (in reference to low education), potential experience, potential experience squared and a female dummy variable (left panel), and task categories in addition (right panel). All coefficients plotted are statistically significant at the $1 \%$ confidence level. Wages above the social security contributions ceiling (right-censoring) have been imputed using a Tobit estimation. 


\section{Appendix}

Table A1: Median Log Wage Growth for All Labor Market Entrants by Education Group

\begin{tabular}{lrrrr}
\hline \hline Cohort & High-Uni & High-FH & Medium & Low \\
\hline $1976 / 77$ & 18.1 & 19.8 & 35.2 & 22.0 \\
$1978 / 79$ & 19.6 & 21.4 & 30.2 & 13.5 \\
$1980 / 81$ & 23.9 & 24.2 & 31.8 & 18.8 \\
$1982 / 83$ & 30.3 & 26.4 & 38.3 & 27.8 \\
$1984 / 85$ & 27.9 & 36.1 & 40.3 & 25.7 \\
$1986 / 87$ & 27.1 & 29.7 & 38.5 & 25.3 \\
$1988 / 89$ & 22.1 & 22.5 & 31.2 & 16.8 \\
\hline $1990 / 91$ & 18.5 & 19.2 & 23.4 & 12.2 \\
$1992 / 93$ & 18.0 & 14.8 & 16.0 & 10.6 \\
$1994 / 95$ & 23.9 & 25.0 & 20.4 & 15.6 \\
$1996 / 97$ & 28.4 & 31.6 & 19.7 & 24.2 \\
$1998 / 99$ & 27.4 & 27.1 & 18.7 & 29.3 \\
\hline $2000 / 01$ & 21.1 & 12.6 & 11.6 & 17.0 \\
$2002 / 03$ & 18.7 & 13.5 & 9.5 & 18.9 \\
$2004 / 05$ & 22.2 & 17.7 & 13.9 & 31.3 \\
\hline \hline
\end{tabular}

Source: $2 \%$ IABS Sample for full-time workers between 25 and 35 years of age. $\mathrm{N}=438,414$.

Note: The table displays the difference between the median log wage for workers with a potential experience of five years and a potential experience of 0 years multiplied by 100 for each educational attainment. 